\title{
ANTEGRADE INTRAMEDULLARY FIXATION OF HUMERAL SHAFT FRACTURES WITH INTERLOCKING NAIL - AN ANALYSIS OF COMPLICATIONS
}

Arvinder Singh ${ }^{1}$

\section{HOW TO CITE THIS ARTICLE:}

Arvinder Singh. "Antegrade intramedullary fixation of humeral shaft fractures with interlocking nail - an analysis of complications". Journal of Evolution of Medical and Dental Sciences 2013; Vol. 2, Issue 45, November 11; Page: 8795-8800.

ABSTRACT : Fractures of the humeral shaft account for 3\% of all the fractures. Primary cause of these fractures is high energy traumas. Goals in managing these fractures are osseous union, minimal deformity and return of maximal extremity function. The union rate of simple fractures of humerus treated conservatively is over $90 \%$. Surgical management of these fractures is preferred in Segmental fractures, Polytrauma patients, Pathological fractures, Open fractures, Failed conservative treatment, Associated progressive neurological deficit, Vascular injury, Morbid obesity.

We analysed intraoperative and postoperative complications in twelve patients with humeral shaft fractures managed with antegrade interlocking nails. There were seven mal es and five females. Their ages ranged between 20 - 60 years with an average of 32.6 years. There were 11 close and one Gustilo grade I open fractures. There were six comminuted, four transverse, and two oblique fractures. Nine fractures were in middle third one in proximal third and two in distal third. Five patients had associated injuries.

We faced difficulty in localizing entry portal in 2 patients. There was difficulty in reduction in 2 patients We had one patient with iatrogenic comminution. Three patients had improper locking screw size. One had nail protrusion proximally, one patient had distraction at the fracture site. There were two superficial entry portal skin infections and one deep proximal cross screw infection. We had two patients with shoulder and one patient with elbow stiffness. Chronic rotator cuff irritation was present in three patients. We recorded three delayed unions, one nonunion and one rotatory malunion

The results of the present study indicate that antegrade intramedullary interlocked nailing is one of the best method of treatment among the currently available methods.

INTRODUCTION: Fractures of the humeral shaft account for $3 \%{ }^{5}$ of all the fractures. Primary causes of these fractures are RTA, falls from height or other high energy traumas. The primary goals in managing these fractures are osseous union, minimal deformity and return of maximal extremity function. The union rate of simple fractures of humerus treated conservatively is over $90 \% 27$. Open reduction and internal fixation of these fractures is preferred in segmental fractures, polytrauma patients, pathological fractures, open fractures, failed conservative treatment, associated progressive neurological deficit, vascular injury, morbid obesity ${ }^{6}$. Among the various surgical methods for management of humeral shaft fractures is the intramedullary fixation with interlocking nail.

MATERIAL AND METHODS: Twelve patients with humeral shaft fractures underwent intramedullary fixation with antegrade interlocking nails. There were seven males and five females. 
Their ages ranged between 20 - 60 years with an average of 32.6 years. Road traffic accidents and falls were the chief causes of injury. There were 11 close and one Gustilo grade I open fractures. There were six comminuted, four transverse, and two oblique fractures. Nine fractures were in middle third one in proximal third and two in distal third. Five patients had associated injuries. Seven patients were operated within five days of injury, remaining five were operated within 5 to 15 days depending upon the associated co-morbidities or injuries.

Fractures were initially temporarily stabilized in emergency with a $U$ shaped adequately padded cramer wire splint after recording the neurovascular status. I/V antibiotics were started according to the requirements of the case. Radiographs of the humerus were obtained in anteroposterior and lateral profiles including both the shoulder and elbow joints. Patients were taken up for surgery when fit. In case of compound fracture, emergency debridement and lavage followed by definitive internal fixation was done within 8 hrs of injury.

Patients were positioned supine with a foam wedge under the should er. Nailing was done by a standard technique under C-arm control on a radiolucent table. Proximal lockings were done through the jig and distal lockings were done by free hand technique. Post operatively an arm sling was routinely used. In patients with as sociated ipsilateral injuries of forearm, a pop splint was given. Analgesics were administered as and when required. Antibiotics were given according to the individual requirements of the case. Post operative neurovascular status was checked and recorded. Shoulder and elbow movements were initiated as tolerated by the patients. Patients were discharged after removal of suture and followed up in the outpatient department and assessed clinically and radiologically at monthly intervals till the fractures united.

RESULTS: All the events intra operatively and post operatively were systematically noted and categorized into intraoperative and postoperative complications. American shouIder and Elbow Surgeons (ABES) assessment score was used with 13 daily activities requiring full shoulder and elbow movements.

\begin{tabular}{|l|l|}
\hline 1. Use back pocket & 2. Perineal care \\
\hline 3. Wash opposite axilla & 4. Eat with utensil \\
\hline 5. Comb hair & 6. Use arm at shoulder level \\
\hline 7. Carry 10 lb on same side & 8. Dress \\
\hline 9. Sleep on affected side & 10. Pull \\
\hline 11. Use hand overhead & 12. Throw \\
\hline 13. Lift \\
\hline
\end{tabular}

4=Normal, 3= Mild compromise, 2= Difficulty, 1= Great difficulty.

Maximum score $=52$; Minimum score $=13$

A.S.E.S. score of upper limb function

$52-47$ in 5 patients

$46-42$ in 3 patients

41 - 36 in 2 patients

$34-31$ in 1 patients

$<30$ in 1 patient 
We had a union rate of $91.6 \%$ and the mean duration for primary union was 21 weeks.

\section{Intraoperative complications}

We faced difficulty in localizing entry portal in 2 patients. There was difficulty in reduction in

2 patients We had one patient with iatrogenic comminution. Three patients had improper locking screw size. One had nail protrusion proximally, one patient had distraction at the fracture site. There were no cases of primary or iatrogenic neurodeficit, failed locking or violation of the adjacent joint.

\section{Postoperative complications}

There were two superficial entry portal skin infections and one deep proximal cross screw infection. These resolved with antibiotics and local debridement.

We had two patients with shoulder and one patient with elbow stiffness. There were initiated on monitored physiotherapy and they recovered. Chronic rotator cuff irritation was present in three patients, out of these one patient had protruded nail which was removed at 14 weeks once the fracture consolidated, remaining two had persistent symptoms with episodic flare-ups.

We recorded three delayed unions, one nonunion and one rotatory malunion. Nonunion was managed with removal of metal work revision internal fixation with a plate and bone grafting.

Table showing intraoperative and postoperative complications.

\begin{tabular}{|l|l|}
\hline Difficulty in localization of entry portal & 2 \\
\hline Difficulty in reduction & 2 \\
\hline Iatrogenic comminution & 1 \\
\hline Improper locking screw size & 3 \\
\hline Nail protrusion(proximal) & 1 \\
\hline Distraction at fracture site & 1 \\
\hline Infection & \\
Superficial & 2 \\
Deep(proximal locking screw) & 1 \\
\hline Joint Stiffness & \\
Shoulder & 2 \\
Elbow & 1 \\
\hline Chronic rotator cuff irritation & 3 \\
\hline Delayed Union & 3 \\
\hline Nonunion & 1 \\
\hline Malunion & 1 \\
\hline
\end{tabular}




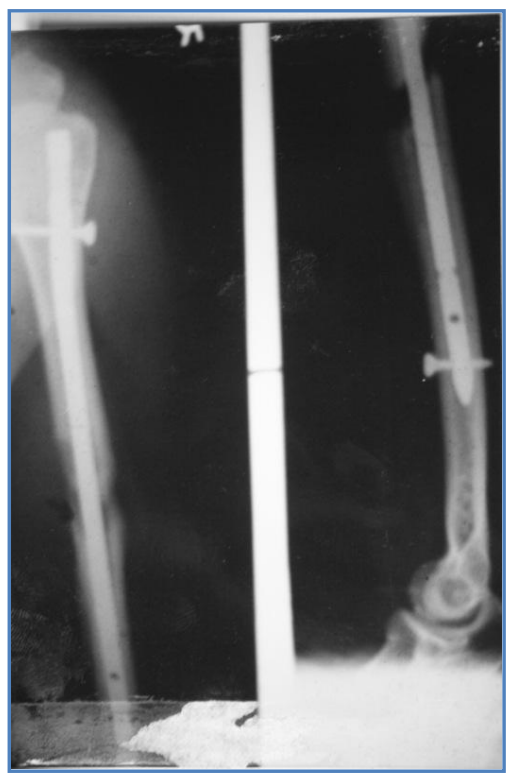

\section{Fig 1: Radiograph showing distraction at fracture site.}

DISCUSSION: Fric et al, $2001^{7}$ reported an average age of 55 years with male to female ratio of 1:2.08. Rommen PM et al, $2008{ }^{1}$ reported a mean age of 63 years.75\% of the fractures were in mid $3^{\text {rd }}$ with one open fracture. Rommen et al, 199517, Ipkeme, 198418 recorded maximum number of fractures in middle third Intraoperative difficulty is encountered in reducing the fractures, especially in closed nailings. There is difficulty encountered in passing the nail in cases where the marrow is narrow and it calls for additional hand reaming. In humerus with narrow medullary canal, distraction at the fracture site can take place (Tapio et al 199910). If narrow medullary canal is not anticipated preoperatively another problem of jammed nail is faced. Ronbinson and court et al, $1992^{22}$ reported a series of 30 humerus nailings and had problems in passing the guide wire for reduction in three transverse fractures. They reported $10 \%$ minimally displaced iatrogenic fractures. Tapio et al in 199910 reported their results and problems in 126 humeral fractures, they had distraction at fracture site in 18 cases. According to Rupp et al, 1996 distraction at the fracture site is the major cause of nonunion. Ingram et $\mathrm{al}^{23}$ they had $16.6 \%$ cases with distraction at fracture site. Osteoporotic bone offers little resistance to drilling and it is difficult to be certain that the screws had passed through the target holes, difficult in proximal locking was seen in $27 \%$ of patients and failed distal locking in 30\%. (Robinson et al, 199222). Moran et al 14 reported missed target in distal locking. Veisei $\mathrm{N}$ et al, $2001{ }^{8}$ had proximal target failure in 5.6\%, iatrogenic comminution in $4.2 \%$ and protrusion in $6.4 \%$. Fric $\mathrm{V}$ et al, $2001^{7}$ reported 42 per operative complications in 23 patients. There were six nail protrusions, fifteen patients had problems with lockings, three patients had iatrogenic comminution. Rommens PM et al, $2008^{1}$ reported iatrogenic comminution in $2 \%$, false placement of lockings in 1\%. Proximal locking is associated with increased risk to axillary nerve. Tapio et al, 199910 reported in one patient, injury to the posterior antebrachial nerve during distal locking. Mc Kee et al, $1996^{13}$ reported three cases of fractures through distal locking screws after the patients sustained a rotational force to arm. Rommens et al, 19981, reported radial nerve palsies in $4.2 \%$. John crates, 1998 , reported $2.7 \%$ of his patients having radial nerve palsy. Tapio et al, 199910 reported 3 intraoperative nerve complications. Proximal migration of intramedullary 
nails caused subacromial bursitis in $66 \%$ of patients( Robinson et al, 199222). According to Ikpeme, 199418 locking screws protruding into deltoid are major cause of pain.

Robinson et al, $1992^{22}$ had two patients with deep infection out of 30 cases. Tapio et al, 199910 had 2 cases of infection in a study of 126 nailings. Rommens PM et al, 20081 reported infection in 15 , nonunion in $3 \%$.

Flinkkila T et al, 199910 stated distraction at the fracture site as the main cause of nonunion. Literature shows an incidence of 0 to $12 \%$ of nonunion with interlocking nail. Bhuller et al 15199614 had 5 nonunions of 17 fractures nailed soon after injury. Robinson et al, $1992{ }^{22}$ reported 7 delayed unions out of 30 fractures. Ingram et al ${ }^{23}$ reported a union rate of $95 \%$ with $90 \%$ uniting within 12 weeks. Robbinson et al 22 observed a mean duration of 18 weeks for union. Hems and Bhullar 15 reported nonunion in $30 \%$ of their cases. Frick V et al, $2001{ }^{7}$ observed a nonunion rate of $15.4 \%$ and no infection. Maurch J et al, $200{ }^{2}$ reported a nonunion in $20 \%$ and shoulder stiffness in $20 \%$.

CONCLUSION: Internal fixation in the patient's with multiple associated injuries hastens recovery, prevents further injury to adjacent soft tissues, prevents and facilitates nursing care and rehabilitation. In the presence of ipsilateral injuries in the same extremely, stabilization of the humeral fracture makes the management easier. The results of the present study indicates that antegrade intramedullary interlocked nailing is one of the best method of treatment among the currently available methods, provided the surgery is meticulously done so that the intra operative complications, particularly tendency for distraction at the fracture site and damage to the rotator cuff are kept to the minimum.

\section{BIBLIOGRAPHY:}

1. Rommens PM et al, Injury 2008, Dec;39(12):1319-28.

2. Maurch J et al Swiss Surg. 2006;(6) 299-203.

3. Petsatodes G et al. J Orthop Sci 2004; 9(3):247-52.

4. Houwelingen AV, McKee MD (2004) Management and Complications of Humeral Shaft Fractures. University of Toronto Medical Journal; 81:96-102.

5. Igbigbi PS, Manda K (2004) Epidemiology of humeral fractures in Malawi. Int Orthop; 28:33841.

6. Campbell's operative orthopaedics - 10th ed, Mosby Publications 2003.

7. Fric V et al Acta Chir Orthop Traumatology Cech 2001; 68(6): 345-56.

8. Vei Sei N et al Wien Klin Wochenschr 2001 Aug 16: 113(15-16): 597-604.

9. Cox MA, et al J Orthop Trauma. 2000 Jun- July; 14(5): 349-53.

10. Tapio Flinkkila et al: Intramedullary nailing of humeral shaft fractures. A study of 126 cases. Acta Orethop Scand. 70(2),132-36:1999

11. John Crates, Paige White: Antegrade Interlocking Nailing of acute humeral shaft fractures. Clin. Orthop.; 350:40-50:May.1998.

12. Tytherleigh-Strong G, Walls N, McQueen MM (1998) The epidemiology of humeral shaft fractures. J Bone Joint Surg Br; 80:249-53.

13. McKee MD, Pedlow FX: Fractures below the end of locking humeral nails. A report of three cases. J Orthop Trauma 10(7). 500-4:1996. 
14. Moran MC - Distal interlocking during intramedullary nailing of humerus. Aug $1995 ; 317$ : 215-8

15. Hems TE, Bhullar TP: Interlocking nailing of humeral shaft fractures: Oxford experience 1991 to 1994. Injury 27(7), 485-9: 1996.

16. Moran MC: Distal interlocking during intramedullary nailing of humerus. Clin Orthop 317, 215 18: 1996.

17. Rommens PM, Verbruggen J, Broos P - Retrograde interlock nailing of fracture of the humeral shaft - a clinical study. Unfallchirurg 1995 Mar ; 98(3) :133-8

18. IKpeme JO: Intramedullary interlock nailing for humeral fractures. Experiences with russel taylor humeral nail. Injury 25, 447-55:1994

19. Ingman AM, Walters DA: Locked intramedullary nailing of humeral shaft fractures. JBJS 76(B), 23-29: 1994

20. Ruf W, Pauly E: Interlocking nailing of humer us. Unfallchirurg;96(6): 323-8: Jun,1993.

21. Rommens PM et al: Locked nailing of humeral shaft fractures. JBJS1992; 74B:558-62.

22. Robinson CM,KM, Bell, CM Court Brown: Locked nailing og humeral shaft fractures. JBJS 1992; 74B:558-62.

23. Brumback RJ, W. Bosse, MJ ; Poka, A : Intramedullary stabilization of of humeral shaft fractures in patients with multiple trauma. 3, Bone Joint Surg. Am), 1986.68 - A : 960 - 9VO.

24. Gustilo RB, Mendoza RM, William DN: Problems in the management of open type fracture: a new classification of type open fracture. J. Trauma, 24: 742-6:1984.

25. Ingram AM. ; Waters DA: Locked intramedullary nailing of humeral shaft fractures. Implant design, surgical technique and clinical results. J Bone J\&t Smg. (Br), 1984, 7\&B : 23-29.

26. Mast, J.W; Spiegel, P.G; Harvey, J.P Harms, C : Fractures of the humeral shaft. Cl Orthop, 1975, U : 254 - 262.

27. Sarmieto, A; Kinman, P; Galvin, E.: Functional bracing of fractures of the shaft of the humerus. JBJS Am 1977, 59 -A : 591 - 601.

\section{AUTHORS:}

1. Arvinder Singh

\section{PARTICULARS OF CONTRIBUTORS:}

1. Associate Professor, Department of Orthopaedics, Gian Sagar Medical College.

\section{NAME ADDRESS EMAIL ID OF THE CORRESPONDING AUTHOR:}

Dr. Arvinder Singh,

Associate Professor, Department of Ortho paedics, 128, Anand Nagar - A, Patial a.

Email - drasingh71@gmail.com

Date of Submission: 18/10/2013.

Date of Peer Review: 21/10/2013.

Date of Acceptance: 29/10/2013.

Date of Publishing: 06/11/2013 